\begin{tabular}{|c|c|c|c|}
\hline & $\begin{array}{l}\text { Escola Superior } \\
\text { de Cestáoe } \\
\text { Tecrologia } \\
\text { [ipsantarém] }\end{array}$ & 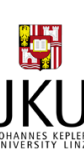 & $\begin{array}{l}\text { ISSN 2029-7564 (online) } \\
\text { SOCIALINES TECHNOLOGIJOS } \\
\text { SOCIAL TECHNOLOGIES } \\
2014,4(1), \text { p. } 62-75\end{array}$ \\
\hline
\end{tabular}

\title{
GAMIFICATION IN FOSTERING CREATIVITY
}

\author{
Marius Kalinauskas \\ Mykolas Romeris University, Lithuania,m.kalinauskas@mruni.eu \\ doi:10.13165/ST-14-4-1-05
}

\begin{abstract}
Purpose - discuss the assumptions for gamification application in fostering creativity.

Design/methodology/approach - the author analyses the precognitions that allowed gamification to attract mainstream attention, the diversity of understandings about the phenomenon, and the possible relations between usage of gamified content and the development of creativity. The paper is based on the comparative analysis of scientific literature and related sources from sociology, business, and entertainment. The engagement is analysed through the theories of self-determination and the "flow". Creativity is understood as "any act, idea, or product that changes an existing domain, or that transforms an existing domain into a new one" (Csikszentmihalyi, 1996). Gamification is analysed as "use of game design elements in non-game context" (Deterding, Dixon, Khaled, and Nacke (2011).

Findings - although gamification is gaining more public attention, studies that would reveal its relations in fostering creativity are lacking. One of the main goals of any gamified platform is to raise the engagement of the participant while keeping the subject interested in the process or activity. In some cases, there is a relation between "flow" and creativity. However, the strength of this relationship depends on the users of gamified content and the domain of interest.
\end{abstract}

Research limitations / implications - there are very few empirical studies that would support correlation between experiencing the "flow" state and the raise of creativity. This issue requires more surveys that would ground the idea. 
Practical implications - by developing further research in the use of gamification while fostering creativity it is possible to determine, whether or not the "creative domains" should apply more measures of gamification in their activities.

Value - the article emphasises the theoretical analysis of gamification and its applicability in fostering creativity. First of all, the context of the rise of gamification is examined. The Generation Y, or the Millennials, is the main target group for gamification applications. The justification of the method is based on the social context formed by a generation of people who like to be stimulated, entertained and engaged. The Millennials are used to advanced technologies; they make the game industry one of the most profitable in the field of entertainment. This creates possibilities for a wider use of game mechanic elements and game thinking in the contexts directly unrelated to games. Furthermore, the definition of gamification is also a controversial issue, since scientists do not agree as to the range of elements that gamification involves. Although gamification is created as a method to increase engagement by using elements of game mechanics, it is explained through theories of self-determination and "flow". The possible correlation between reaching the state of "flow" and fostering creativity is a questionable issue, as only a few studies have focused on the idea.

Research type: general review, viewpoint.

Keywords: gamification, creativity, Millennials, Generation Y, serious games, gameful design.

\section{Introduction}

The context for gamification applications in fostering creativity is one of the first issues to be addressed in this paper. Video game culture recognised by Generation $\mathrm{Y}$ allowed usage of game mechanics in various domains. The so-called Millennials were born and raised surrounded by technologies. They are more confident and more technologically advanced, compared to earlier generations. However, this also has its negative side, such as shorter attention spans or orientation towards various stimuli. The raise of video game industry allowed some significant perception changes towards the usage of gameful design. Gamification is one of phenomenons that has situated the transformations of the perception towards the activities or processes having little or no connection with entertainment.

It is a significantly new trend that may be applied in various domains. The main idea of the methods lies around the usage of game mechanics for coping with real life challenges. Educational, motivational, and business gamification-based platforms began to spread in recent years, thus triggering the positive and negative acclaims alike. However, positive recognition is more obvious and it is likely that the biggest hype, as well as expectations towards gamification are up ahead. Despite that, there is a shortage of academic discussion that would consider gamification as one of the facilitators in raising creativity. There are indirect implications for this idea, especially when games or virtual environments are used for educational or self-expression purposes. Gomes 
(2012) presents the idea and possible definition of "cyberperformance", where virtual environments serve as a medium for an act of expression. The virtual game called Second Life was used as a basis for a project, where the author tried to expand the boundaries between virtual and physical worlds. Dennis, Minas, and Bhagwatwar (2013) used a priming-based game with the members of the group and afterwards gave them the creative task. The results have shown that when users played the game designed to improve performance, their group generated significantly more ideas, compared to the other group that did the tasks without gaming intervention. Moreover, Garaigordobil and Berrueco (2011) conducted an experiment with preschool children and came up with the conclusion that children who were significantly involved in the play programme increased their verbal creativity, graphic creativity, and demonstrated behaviours and traits of creative personality. In this case, a different scenario took place, and virtual gaming was not involved into the process.

The discussion of what should be considered as gamification is still ongoing. For the purpose of this paper, the definition provided by Deterding, Dixon, Khaled, and Nacke (2011) will be used as the basis for describing the method. Authors define gamification as "use of game design elements in non-game contexts". Since gamification is closely related to gaming theories, it is important to distinguish playing and gaming elements. Caillois (1961) raised the concept of paidia and ludus, while putting them into separate poles. Paidia (playing) describes free-form behaviours and meanings based on expression as well as improvisation, and ludus (gaming) is founded on rulebased playing with determined goals and objectives. Although playing and gaming have their differences, it is necessary to note the importance of engagement which serves as a unifying factor for both poles, and is one of the main preconditions towards more original problem solution. Engagement and motivation are closely related with the gamification principles. The ability to use these forces in order to foster creativity would possibly lead to some fundamental changes in many domains where creativity is a must.

However, it is a rather complicated issue, as defining creativity depends on the context of the domain, and the associated theory that serves as a basis for definition. In the context of this paper, creativity is understood as "any act, idea, or product that changes an existing domain, or that transforms an existing domain into a new one" (Csikszentmihalyi, 1996). Originality and ability to adapt to new circumstances, dealing with them in unique ways, are the fundamental factors characterising a creative person. The approaches of creativity may come from various fields and cover art, science or daily activities. Csikszentmihalyi (ibid.) has once stated that "an idea or product that deserves the label "creative" arises from the synergy of many sources and not only from the mind of a single person". He also adds that "it is easier to enhance creativity by changing conditions in the environment than by trying to make people think more creatively". Conformism may lead to reduced creativity because of comparatively safe, known environment and habits, which do not require improvisation or "out of the box" thinking. Torrance (1988) comes to a conclusion that creativity is not only related to the lack of challenge, it is more a feature, or ability to be free from conformation or not conformation, depending on personal understanding of correct 
choices. Gamification serves as one of the facilitators that may "lure" a person out of their comfort zone by providing them with a worthy challenge, which is relatively safe, engaging and effortless (since the burden of "effort" is partially withdrawn by fun and engagement provided by the gamified platform). The relatedness with the goal, story or community allows searching for original problem solutions or behavioural changes. However, the domain must be gamified wisely and should not violate the autonomy of an individual. Gamification is just an alternative of "doing things", and as all alternatives, it may have its positive and negative sides.

From the methodological standpoint, this paper is presented as general review/ viewpoint. The main purpose of the article is to discuss the assumptions for gamification application in fostering creativity. First two chapters discuss gamification and creativity (in their broad sense). The third chapter analyses gamification as the method for fostering creativity. The paper is based on the comparative analysis of scientific literature and related sources of sociology, business, and entertainment industries. It is expected to raise a discussion that would lead to empirical study of gamification effect to creative performance. The paper is limited by its theoretical nature, as well as broad definition of creativity, since it could be explained in different ways, depending on the specific domain.

\section{The Ludic Rise of Generation Y}

Howe and Strauss (2000) have raised the idea of a new generation that followed the Generation X. Nimon (2007) noted that there was a debate of how to call this group, as well as the disputes concerning their starting and ending points in the timeline. The term letter settled as Generation Y, or the Millennials. Although there is no strict agreement as to dates, it is considered that these are the people who were born from the early 1980s to the early 2000s. In order to describe this generation it is necessary to evaluate technological and social context that formed the fundamental values and abilities of the Millennials. Nimon (ibid.) claims that the arrival of the millennial generation coincided with the development of ICT products, such as personal computers, virtual networks, mobile devices, etc. These technologies transformed the society, influenced its abilities, values and skills. The Millennials were at the centre of technology development, they unwillingly participated in "silent revolutions" which transformed many areas of daily lives. The most notable changes were related to the emergence of new service models, technologies, and communication channels. The principles of interaction, socialisation and entertainment were affected as well. In communication Millennials prefer to be connected via the internet or mobile devices. They greet technological innovations with trust and comfort, this does not mean however that Millennials examine the structure or nature of technologies. They are the adapt users, the progeny of networked digital rise, where reality and virtual worlds blend together.

Video games were among the most notable products created as an outcome of this blend. This sector increased the market share in the entertainment industry, and now 
is one of the most profitable areas in the field. According to Entertainment Software Rating Board (2013), 67\% of US households play video games. $49 \%$ of gamers are between $18-49$ years old, and the average gamer is 32 years old. IT research and advisory company Gartner (2013) claims that the global video game market share on video games will reach USD 111 billion by 2015. The more detailed numbers concerning the video game industry forecasts are provided in Figure 1. These numbers show that virtual reality is a tempting place to be, especially for the people born and grown with it. There are some examples showing that virtual worlds still have not reached their full potential. The video game Grand Theft Auto 5 (GTA 5) proved that sales of one game may outsell the entire global music industry, which generates monthly record and song sales of USD 1.4 billion (Daily Finance, 2013). According to Metro and Cnet websites (2013), the budget of GTA 5 was USD 265 billion. However, the investment paid off since the game earned USD 800 million in only 24 hours. The other example a game which is more of a gamification platform, called The Rocksmith. Since its release in 2011, the game sold more than 1.4 million units worldwide (VGChartz, 2013). The game is designed as a platform for learners to play the guitar, it involves interactive progress meters, original soundtracks and sound effects, gamified practice modes, it also uses an electric guitar as a controller. This is the first big budget blend of game/gamification conceptions which was positively received by gamers and critics alike. These examples show that video games have become a very influential form of entertainment. Rise of gamified platforms gain positive recognition and broaden the understanding about training and education. Not only the Generation $\mathrm{Y}$ is the target group for these kinds of games, they create precognitions for the game industry to be profitable, which leads to higher budget project, public attention, and eventually, research in the area.

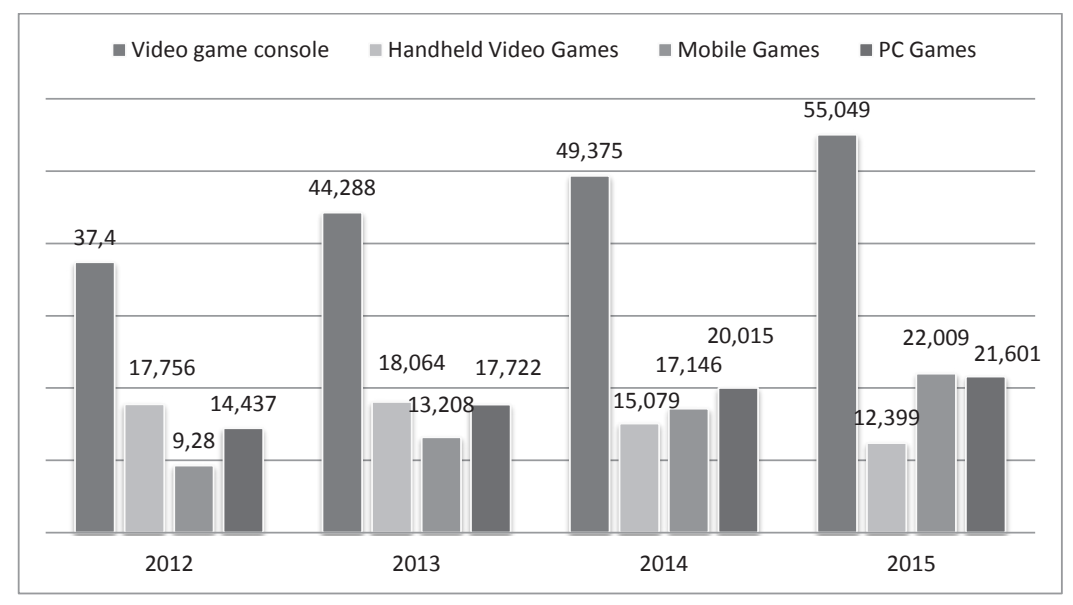

Figure 1. Forecasted Video Game Market Revenue, Worldwide, 2012-2015 (Billions of Dollars). Source: Gartner, 2013

Millennials are thirsty for entertainment as well as willing to pay generously in order to be engaged into activities of virtual worlds. However, this involvement has 
its flipside. Despite the benevolence toward technologies, the Millennials suffer from some issues that were not present with the previous generations.

They are more influenced by a constant flow of information and expect immediacy (Skiba, 2005), which makes them dependant on various forms of stimulation. Sheahan (2005) notes that Millennials are less affected by the outside opinions, they are overconfident, and want to be entertained. It may sound as critical claims towards the Generation Y, and part of this criticism is well-grounded. However, there are few misconceptions relating to the Millennials. First of all, they are not necessarily natives with the technologies. They are pushed to become ones instead. Nowadays, the completion of a simple daily task requires ICT intervention, so it is natural that people adapt to requirements, thus mastering the technologies. Secondly, the uncertainty about life conditioning factors (i.e. economic situation, labour market, place of residence, etc.) requires quick reaction times in order to cope with changes. This may result in a short attention span, which leads to boredom, distraction and a lack of motivation. However, the engagement factor serves as a stabiliser, and video games are known as one of the most engaging forms of entertainment. It is possible to use elements of game mechanics for additional engagement thus expanding the boundaries for creative problem solution. Millennials are used to the technologies and are familiar with digital worlds. They are anxious for entertainment, stimulus and a sense of achievement. If used correctly, video games may provide this stimulus. The growth of the video game industry shows the existence of great potential for the use of game mechanics in the contexts directly unrelated to entertainment. This is where gamification steps in. Although games and gamified environments have a lot in common, there are some differences that need to be cleared out and defined.

\section{The Essence of Gamification}

During the last few years the trend of gamification has gained significant attention. The conception of game-thinking or usage of game mechanics was known long before the term "gamification" appeared. Rule-based games had various purposes, starting from purely entertainment genre, and ending up with some higher objectives, such as obtaining new knowledge and skills. Video games raised the bar and strengthened the positions of "gaming", since both - traditional rule-based games and video games reflect the ludic nature. In both cases gameful design is used as a foundation for the genre. The elements of game mechanics as well as gameplay may be applied in later stages. Serious games also fall into category of "gaming", however, they tend to deliver something more than just pure entertainment. The military uses "serious games" in order to familiarise soldiers with the subtleties of the battlefield, pilots are trained in flight simulators where they operate the aircraft with no risk of fatal consequences, children and adults may use edutainment games that are a mix of games and educational platforms. Despite that, gamification is different from previous cases. It is also related to gaming rather than playing, and uses some elements specific to serious games. However, gamification does not focus on the gameplay and 
entertainment parts. though may use these elements while increasing engagement. The term itself causes controversial opinions among interested parties. Deterding, Dixon, Khaled, and Nacke (2011) generalise the discussion towards the definition of gamification, emphasising the variety of names given to the phenomenon. According to those authors, "the first documented use of the term dates back to 2008, but the term did not see widespread adoption before the second half of 2010". It is also noted that other concepts like "productivity games", "surveillance entertainment", "funware", "behavioural games", "game layer", "applied gaming" are also present. However, "gamification" is still the most popular term despite constant challenging. According to Zichermann and Cunningham (2011), gamification may be defined as "the process of game-thinking and game mechanics to engage users and solve problems". Deterding et al. (ibid.) defines gamification as "use of game design elements in non-game contexts". The non-gaming contexts should be understood as a dissociating factor that draws a line between the use of elements of game design and game design as part of game creation. These domains are not identical, thus if the context of gamification is directly related to creation or support of the game, it becomes an object of game design and not an object of gamification. In both definitions, game mechanics (game design elements) play crucial roles in the delivery of gamification. The purpose of a gamified platform is to create an engagement medium or activity that would engage the user in its content. The use of badges, leader boards, point systems and levelling is only a helping factor that does not determine the success of gamification. The reward must not be based on the false sense of achievement; it should create true value and natural involvement. Some authors (Hamari and Eranti, 2011) express technocratic perspective towards gamification, however the true potential of this concept lies in the ability to attract users and engage them. In case of successful gamification as a tool, process or system, it is possible to engage a specific audience towards a set of behaviours, skill development and provide goals, rules and tools for gamers to explore experiment, collaborate and solve complex problems.

Nevertheless, the demand for solution of problems does not derive from the necessity to do so. The more important factor is motivation to participate in the gaming process. Lucas, Sherry, et al. (2003) have applied uses and gratifications theory, created by Blumler and Katz (1974), and created the taxonomy that named the reasons of engagement into gaming. According to their findings, people play video games thus seeking to access one or few of the following psychological states: (a) competition the ability to outrival the others; (b) challenge - success related to the completion of a worthy task; (c) diversion - an option to escape from stress; (d) fantasy - express unrealistic feelings; (d) social interaction - ability to connect with other, (f) arousal gaining positive stimuli. These elements disclose the main reasons for participating in the game. However, it does not explain the full spectrum of human needs in a broader sense, and how these needs associate with the engagement in video games. In order to answer these questions it is necessary to look for a macro theory which would combine in-game engagement process in the context of basic psychological needs of an individual. 
The self-determination theory by Deci and Ryan (2000), systematically explains the phenomenon, which stands as a basis for engagement into gamified activities. This is one of the most popular theories among the advocates and critics of gamification alike. The study of Przybylski, Rigby and Ryan (2010), which used self-determination theory as a basis, has revealed that at least three factors make independent impact on game engagement in short term:

- autonomy - sense of choice and psychological freedom, ability to influence the gameplay;

- competence - the feel of effectiveness in game;

- relatedness - needs, the feel of connectivity and interaction with others.

According to those authors, "appeal of games is based on the psychological need satisfaction play can provide". It is also noted that influences of video games on players may vary, and that there is dependency between psychological needs satisfaction and engagement into gaming. Games can enhance wellness or aggression, depending on the satisfaction level of universal needs for competence, autonomy, and relatedness. These three elements define the basic characteristics which encourage a person to stay in the virtual world. In some cases, when the needs related to psychological satisfaction are not fulfilled, the person may be obsessively engaged in gaming thus unable to feel the enjoyment of it. Schoenau-Fog (2011) conducted a study, where he investigated "one dimension of player engagement by empirically identifying the components associated with the desire to continue playing". The author analyses the factors that situate involvement into game and the reasons why individuals keep playing. The results of the survey showed that the answers about the engaging factor may be distributed into four categories, all of which situated the continuity of playing computer games. The categories are as follows: (a) objectives - the extrinsic and intrinsic motivators which keep the player going, (b) activities - the actions which player is willing to do in order to reach the objectives, (c) accomplishment - the result of fulfilling the objective, (d) affect - experience and emotional response toward the completion of objective. The author also notes that the results of his study have some findings and common characteristics with other theories, and support the survey results of Yee (2006), Ermi and Mäyrä's (2005), and Klimmt's (2003). Schoenau-Fog recognises that the affect subcategory labeled "absorption" is strongly related to the concepts of "flow" developed by Csikszentmihalyi (1975).

The "Flow theory" examines the state of satisfaction or happiness and is very popular in various domains. People in a state of "flow" are those who feel they are engaged in a creative unfolding of something larger, whether it's a video game, sport competition or an act of art. The "flow" is directly related to the engagement in the process. During this state the knowledge or emotions absorption rate is increased and the involvement into activity reaches its maximums. "Flow" is a line between boredom and anxiety, when a subject is challenged enough to be interested. Groth (2012) adds that in the sense of gamification, it is useful to modify the difficulty level inside the "flow". "Even failures are desired, because it improves the experience of mastering the challenge thereafter". Every game and gamification platform tries to keep the gamer inside the "flow". This is done to balance the difficulty level and to give adequate reward 
for the progress. However, the affect of flow towards creativity is a less researched area. Although gamification is promoted as a method that encourages users to be involved in the ongoing activities, it does not position itself as a fostering tool for creativity.

\section{Gamification in Fostering Creativity}

The use of technology in fostering creativity is nothing new, since the technology itself is a product of a creative mind. Even a human being is the result of creativity, since $98 \%$ of our genome matches the one of the chimpanzees, and the things that distinguish us are scientific understanding, language, technology and values (Csikszentmihalyi, 1996). The society was transformed by information technologies, together with the processes related to work, entertainment or education. Creativity, as an ability to produce something new, usable and meaningful is among the most researched fields in psychology (Mumford, 2003). Moreover, some authors claim that the issue of creativity should be stressed with greater effort, since transformations in the society signal about greater demand for creative potential, moreover, those groups which demonstrate high creativity, generate more additional value for the general population (Florida, 2002, Pink, 2005). Despite the criticism towards this approach, it is clear that creativity and creative thinking is becoming a valuable resource, since social and economical structures are becoming more dynamic.

The studies on creativity are quite popular in the academic world, and a number of theories exist about the underlying constructs of creativity, "theories attributing it to everything from method to madness - none of them very satisfactory". As to inducing creativity - by using heuristic strategies or through "creativity training" this has had very limited success (Harnad, 2007). Creativity is a phenomenon, a trait, which cannot be defined in an easy way, and, according, to Boden (1994), the very concept is seemingly paradoxical, since it is based on intuition and strives to "create something from nothing". Moreover, creativity is related to novelty, originality, value, unexpectedness and the knowledge base, which is used as a background for creative ideas (Harnad, ibid.). In order to be able to approach issues creatively it is necessary to develop a critical attitude towards the environment by raising questions about the correctness of the surroundings, and developing the ability of "intentional creativity" (Schank, Cleary, 1993). But what is the role of ICT, games, and gamification in the context of creativity? The common opinion is that computerised systems are not creative, and they cannot achieve the performance that humans can. However, the presence of ICT in the creative process is becoming a norm, since there are so many tools and the virtual environments that empower an individual to perform better, faster, and with less effort while achieving the result. But the statement that ICT may serve as a factor for fostering creativity is controversial.

Lubart (2005) expresses his position about the role of ICT in creative approach. He recognises technologies more as an organisational tool that allows lessening the burden of time-consuming secondary tasks while developing creative content. It is possible to use expert systems as a content producer, and, according to Boden (ibid.), 
computer systems can eventually understand creativity and demonstrate creative abilities. Todd (1989) trained a neural network to make musical melodies out of the given samples. The author noted that the human verdict is still needed as to whether the melody sound is pleasing or not. However, Harnad (ibid.) argues that since computers operate based on algorithms and machine logics, they do not demonstrate creative abilities, because algorithm is based on a set of rules which develop in a predictable way. Maher (2012) sees machine-based creativity as collaboration between the computational system and a human. She claims that "as we develop a better understanding of processes and products in creative people or systems, we are able to develop more capable computational creativity". To sum it up, there are mixed approaches towards the issue, and the spectrum of opinions varies from supporting to denying the possibility of computational creativity. Therefore, maybe there are reverse possibilities for machine-based creativity? May the use of ICT measures, including games and gamified platforms, raise the creativity of a group or an individual? In order to answer these questions it is necessary to highlight the main elements of games and gamified platforms related to creative performance.

Firstly, creative activities and gaming may be grounded on the same selfdetermination theory. Sheldon (1995) came with the assumption that self-determined people, who are better at controlling factors, with the resulting negative impact on creativity are better at establishing and maintaining contact with intrinsic factors. His studies revealed that, "Although a disposition to be self-determining may be useful to people engaged in creative pursuits, a person who is self-determined is not necessarily a person who is creative". Self-determination is only one of the many factors that influence creativity. The autonomy level of an individual is also associated with creative performance, and people who are better with making choices also have a stronger potential for creative practices (Sheldon, ibid.). The extrinsic stimuli are nonetheless important for the creative approach, since they reinforce or suppress the intrinsic motivation. Deci and Ryan (ibid.) state that extrinsic rewards may be tangible and intangible, thus ensuring the alike affect to motivation. Video games are creating an environment of entertainment, which strongly relies on this conception while ensuring the realisation of autonomy, competence and relatedness. The intrinsic and extrinsic motivators that keep a gamer involved serve as a basis for engagement, and in some sense relate to the fulfilment of basic psychological needs. Although this cannot be directly related to the development of creativity, both elements partially rely on intrinsic motivation as a facilitating factor for (a) engagement, (b) increased creativity potential, which could be exploited or not. In case of gamification - it uses the same game design elements which ensure interest and involvement into activities. Since properly gamified domain may have a positive boost on motivation, later on it may influence self-determination, which, according to Sheldon (ibid.), in the long run influences creativity, since an individual is more willing to spend more time and effort while searching for solution to the problem. Another important issue when discussing motivational aspects of gamification is related to feedback. It is one of the crucial elements that work as an extrinsic stimulus in reinforcing the intrinsic motivation. Moreover, the correct feedback may lead to an original problem solution, 
since the essence of gamification lies in using game mechanics in non-game contexts. Creative approach towards the problem could be determined by quality gamification practices in a specific domain. Foster, Sheridan, et al. (2012) created a gamified course on learning of reverse engineering, which promoted identifying and understanding activity from a design perspective. The authors came to a conclusion that learning process still "requires cognitive development that no game can overlap". However, they have added that gamified process motivates cognitive development by creating stimulating, playful and exploratory learning environment. These factors have resulted in deeper engagement into educational process, and allowed experiencing new approaches towards reverse engineering, as well as broadened the knowledge base of students. The knowledge level about the domain is one of the main factors towards creative thinking. It empowers search for "alternative routes" for problem solving and serves as one of the key elements for fostering creativity.

Secondly, since gamification tries to engage the user into activity, it would be useful to examine the relation between "flow" and motivation. Macdonald, Byrne and Carlton (2006) conducted a study designed to investigate the relationship between flow and creativity in the context of musical education. The authors revealed that "higher levels of flow are related in a number of important ways to higher levels of creativity and higher quality compositions". The authors have also noted that gamification of specific domains must be cautious, especially in the areas where creative result is dependant on the performance of the group. This may be also applied in the gamification context, since too high or too low requirements for the achievement of the goals distance the participant from the activity, which eventually may end in the critical decrease of motivation, and negative effect towards creative performance. Since the researches in this area are sparse, it is hard to strongly agree with the idea that the state of "flow" is related to creativity in a wider spectrum of domains. However, "flow" allows spending more time with the activity and experiencing higher engagement rates, which again influences the skills and knowledge base of a person.

\section{Conclusion}

Gamification is becoming a trend that has many critics and advocates alike. The debates about this conception have gained more notable significance in 2010, and now the attention towards the idea is rising. The popularity precognitions for gamification come mostly from the Millennials, or the Generation Y. These people were raised next to technologies and have been at the centre of various social transformations situated by the penetration of ICT. The strength and profitability of video-game industry allowed taking a new turn towards the use of gameful thinking and elements of game mechanics. There is a lot of criticism towards the term "gamification", scientists agree, however, that it may trigger the same elements of motivational behaviours as video games do. The self-determination theory is among the most popular foundations for the explanation of engagement into gamified activities. In the context of gamification, creativity may be related to the self-determination theory as well as to the theory of 
"flow". Since gamification may cause higher engagement into activity, it is likely that a person may gain additional knowledge about the domain, thus developing one of the most important features in creative performance. The engagement is mostly accessible through the state of "flow", which could be related to enhanced creativity. However, there are very few empirical studies that analyse the relationship between these two categories, so that a generalised claim that being in the state of "flow" serves as the facilitator for fostering creativity would be rushed. This area needs the attention from scientists in its broader context. The review of scientific studies has revealed some possible parallels between creativity and gamification. Engagement in gamified activities encourages solving problems in various ways, and the spectrum of the solutions may lead to new, original and valuable methods on dealing with issues. Properly gamified content may encourage "flow" states, so it is plausible that a person spending more time and efforts while gathering the experience in the domain may lead to increased creativity, since "knowledge base" is one of the criteria for one being creative. The biggest challenge so far lies in gamifying different domains, since inappropriate application of elements of game mechanics could lead to a loss of motivation. To sum it up - gamification is a new and controversial trend that is gaining more significance from various parties. It may serve as one of the factors fostering creativity in some domains; however, the more general conclusion about that relationship should be grounded on empirical studies in the future works.

\section{References}

Blumler, J., \& Katz, E. 1974. The uses of mass communications. Beverly Hills, CA: Sage.

Caillois, R. 1961. Man, Play, and Games. University of Illinois Press, Urbana, Chicago, 2001.

Csikszentmihalyi, M. (1975). Beyond boredom and anxiety. San Francisco, CA: Jossey-Bass.

Csikszentmihalyi, M. (1996). Creativity: Flow and the psychology of discovery and invention. New York, NY: Harper Collins Publishers.

Csikszentmihalyi, M. (2008). Flow: The Psychology of Optimal Experience. ser. P. S. Series. HarperCollins.

Daily Finance website. 2013. GTA 5 Sales Hit \$1 Billion, Will Outsell Entire Global Music Industry. [interactive]. [accessed 2014-01-16]. <http://www.dailyfinance. com/2013/09/28/gta-5-sales-hit-1-billion/>.

Dennis, A. R, Minas, R. K., Bhagwatwar, A. P. (2013). Sparking Creativity: Improving
Electronic Brainstorming with Individual Cognitive Priming. Journal of Management Information Systems, p. 195-215.

Deterding, S. Dixon, D. Khaled, R, Nacke, L. (2011). Gamification: Toward a definition. CHI 2011 gamification workshop.S.

Deterding, S. Dixon, D. Khaled, R., Nacke, L. (2011). From game design elements to gamefulness: Defining gamification. MindTrek '11 Proceedings of the 15th International Academic MindTrek Conference: Envisioning Future Media Environments.

Entertainment Software Raiting Board website. 2013. Video game statistics. [interactive]. [accessed 2014-01-16]. <http://www.esrb. org/about/video-game-industry-statistics. jsp>.

Ermi, L., \& Mäyrä, F. (2005) Fundamental components of the gameplay experience: Analysing immersion.n Changing Views: 
Worlds in Play. Selected papers of the 2005 Digital Games Research Association's Second International Conference, DiGRA, p. 15-27.

Florida, R. (2002). The Rise of the Creative Class: And How it's transforming work, leisure, community and everyday life. New York: Perseus Book Group.

Foster, J. A., Sheridan, P. K., Irish, R. Frost G. S. (2012). Gamification As A Strategy For Promoting Deeper Investigation In A Reverse Engineering Activity. American Society for Engineering Education.

Garaigordobil M., Berrueco L. (2011). Effects of a Play Program on Creative Thinking of Preschool Children. The Spanish Journal of Psychology Vol. 14, No. 2. P 608-618.

Gartner website. 2013. Forecast: Video Game Ecosystem, Worldwide, 4Q13. [interactive]. [accessed 2014-01-16] <https://www. gartner.com/doc/2606315>.

Gomes, C. (2012). For a definition of cyberformance. Proceedings of the SLACTIONS 2012 International Conference Life, imagination, and work using metaverse platforms, p. 31-35.

Groth, F. (2012). Gamification: State of the Art Definition and Utilization. 4th Seminar on Research Trends in Media Informatics. Conference Paper., p. 39-46.

Hamari, J. and Eranti, V. 2011. Framework for Designing and Evaluating Game Achievements. Proc. DiGRA 2011: Think Design Play, DiGRA.

Harnad, S. (2007). Creativity: Method or Magic? In: H. Cohen and B. Stemmer (eds.) Consciousness and Cognition: Fragments of Mind and Brain Amsterdam: Elsevier Academic Press, 127-137.

Howe, N., \& Strauss, W. (2000). Millennials rising: The next great generation. New York: Vintage Books.

Klimmt, C. (2003). Dimensions and determinants of the enjoyment of playing digital games: A three-level model. Level Up: Digital Games Research Conference (Utrecht, Netherlands, November 2003). University of Utrecht \& DiGRA., p. 246-257.
Lubart, T. (2005). How can computers be partners in the creative process: classification and commentary on the special issue. International Journal of Human-Computer Studies - Special issue: Computer support for creativity, 63(4-5): 365-369.

Macdonald, R., Byrne, C., Carlton, L. (2006) Creativity and flow in musical composition: an empirical investigation. Society for Education, Musicand Psychology Research, 34(3): 292-306.

Maher, M. L., (2012). Computational and collective creativity: Who's being creative? Proceedings of the Third International Conference on Computational Creativity.

Mumford, M. D. (2003). Where have we been, where are we going? Taking stock in creativity research. Creativity Research Journal, 15, 107-120.

Nimon, S. (2006). Generation Y and higher education: The other Y2K. Journal of Institutional Research, 13(1): 24-31.

Pink, D. H. (2005). A Whole New Mind: Moving from the information age into the conceptual age. Allen \& Unwin.

Przybylski, A. K, Rigby, C. S., Ryan R. M. (2010). A Motivational Model of Video Game Engagement. Review of General Psychology, 14(2).

Ryan, R. M., Deci, E. L. (2000). Selfdetermination theory and the facilitation of intrinsic motivation, social development, and well-being. American Psychologist, 55: 68-78.

Schank, R. C., Cleary, C. (1995). Making Machines Creative. In: S Smith, T B Ward $\& R$ A Finke (eds) The Creative Cognition Approach. MIT Press. 229-247.

Schoenau-Fog, H. (2011). The Player Engagement Process: An Exploration of Continuation Desire in Digital Games. Proceedings of DiGRA 2011 Conference: Think Design Play: Fifth international conference of the digital games research association Vol. 2011 Utrecht University : Digital Games Research Association.

Sheahan, P. (2005). Generation Y: Thriving and surviving with generation $Y$ at work. 
Prahran, Victoria, Australia: Hardie Grant Books.

Sheldon, K., M. (1995) Creativity and SelfDetermination in Personality. Creativity Research Journal, 8(1): 25-36.

Sherry, J., \& Lucas, K., Greenberg, B. S., Lachlan, K. (2003). Video game uses and gratifications as predictors of use and game preference. Presented at the Mass Communication Division, International Communication Association Annual Convention, San Diego, CA.

Skiba, D. J. (2005). The millennials: Have they arrived at your school of nursing? Nursing Education Perspectives, 25(6): 370-371.

Todd, P. M. (1992). A connectionist system for exploring melody space. In Proceedings of the 1992 International Computer Music Conference. San Francisco: International Computer Music Association, p. 65-68.
Torrance, E. P. (1988). The nature of creativity as manifest in its testing. In Sternberg, R. J. (Ed.). The nature of creativity: Contemporary psychological perspectives. Cambridge: Cambridge University Press, p. 76-98.

VGChartz website. (2014). The sales of The Rocksmith. [interactive]. [accessed on 2014-01-16]. <http://www.vgchartz.com/ game/50574/rocksmith/>; <http://www. vgchartz.com/game/50573/rocksmith/>.

Yee, N. (2006). Motivations for Play in Online Games, in CyberPsychology \& Behavior, 9(6): 772-775.

Zichermann, G., Cunningham, C. (2011). Gamification by Design: Implementing Game Mechanics in Web and Mobile Apps. O’Reilly Series. O’Reilly Media. 